\title{
Bed-Load Diversion with a Vortex Tube System
}

\section{Conference Paper}

Author(s):

Rachelly, Cristina (D); Albayrak, Ismail (D); Boes, Robert (iD; Weitbrecht, Volker (1)

Publication date:

2019-09-06

Permanent link:

https://doi.org/10.3929/ethz-b-000370865

Rights / license:

In Copyright - Non-Commercial Use Permitted

Originally published in:

Proceedings of the IAHR World Congress, https://doi.org/10.3850/38WC092019-0718

Funding acknowledgement:

727830 - Fishfriendly Innovative Technologies for Hydropower (SBFI) 


\title{
BED-LOAD DIVERSION WITH A VORTEX TUBE SYSTEM
}

\author{
CRISTINA RACHELLY(1), ISMAIL ALBAYRAK(1,2), ROBERT M. BOES ${ }^{(1)} \&$ VOLKER WEITBRECHT(1) $^{(1)}$ \\ (1) Laboratory of Hydraulics, Hydrology and Glaciology (VAW), ETH Zurich, Switzerland \\ (2) albayrak@vaw.baug.ethz.ch (corresponding author)
}

\begin{abstract}
Impaired sediment connectivity in river systems due to transversal hydraulic structures is a primary cause of channel narrowing and down-cutting, as well as reduced morphodynamic variability. Among various restoration measures, the vortex tube is a structural measure to re-establish bed-load conveyance during flood events at low-head hydraulic structures. Bed-load particles are entrained through a slit in the tube soffit and sluiced from an upper channel to a lower parallel channel. This paper presents and compares the results of two laboratory model studies on the optimal design of vortex tubes for run-of-river hydropower plants. Although the two case study hydropower plants are situated within $1.5 \mathrm{~km}$ distance along the same river, differences in boundary conditions considerably reduce the suitability of one of the plants for the effective operation of a vortex tube. The test results show that the energy head difference between the two channels is a decisive hydraulic boundary condition and should be larger than approx. $1 \mathrm{~m}$ at all times. The dimensions of the vortex tube should be adapted to the grain sizes of the transported bed-load. If the vortex tube does not span the entire channel width, an open tube end is recommended to increase its zone of influence. A diversion efficiency of $94 \%$ was determined for the optimal design. The present findings demonstrate that vortex tubes may be an appropriate structural measure to re-establish sediment continuity at hydraulic structures, primarily where the upstream and downstream channels are located in close proximity.
\end{abstract}

Keywords: vortex tube, sediment connectivity, bed-load transport, bed-load diversion

\section{INTRODUCTION}

Sediment transport with its inherent temporal and spatial variability is a vital component of natural river systems (Wohl et al., 2015a). In many river systems, however, infrastructures such as hydropower plants (HPPs), dams, weirs, sediment traps, and gravel extraction sites interrupt the longitudinal sediment transport connectivity. The resulting reduction of sediment transport may cause channel down-cutting, narrowing, and the impairment of the transversal connectivity between the main channel and its floodplain (Kondolf, 1997). Furthermore, reduced sediment transport may result in impoverished morphodynamic variability, which is in turn often connected to a shortage of suitable habitats for riverine flora and fauna and reduced ecological resilience (Wohl et al., 2015b). In addition, channel down-cutting may seriously threaten the stability of hydraulic structures, such as bridges and bank protection (Kondolf, 1997). Bed-load entrainment into the headrace channel and powerhouse of HPPs during flood events may damage the turbines, require intensive maintenance works, and cause operational disturbances.

Due to the detrimental effects of reduced sediment transport on river ecosystems and hydraulic structures, it is important to include sustainable sediment management in operational frameworks and restoration strategies. Mitigation measures against sediment deficit include (i) structural measures, e.g. sediment bypass tunnels or vortex tubes, (ii) operational measures, e.g. reservoir drawdown during natural or artificial flood events, and (iii) sediment replenishment (Bunte, 2004; Boes, 2015; Boes et al., 2017; Sumi, 2017).

This paper focuses on the vortex tube, a structural measure to convey bed-load from the upstream to the downstream reach of transversal structures, e.g. low-head run-of-river (ROR) HPPs. It summarizes the findings of two laboratory model studies on the design and diversion efficiency of vortex tubes planned for two HPPs in Switzerland and discusses their operating principle and application range. At one of these HPPs, a vortex tube was constructed in the year 2003. Both studies were commissioned by Limmatkraftwerke AG in Baden, Switzerland.

\section{THE VORTEX TUBE SYSTEM}

The concept of vortex tubes originates from irrigation engineering as a measure to prevent sediment deposition in irrigation channels and the resulting reduction of their conveyance capacity. Compared to the continuous diversion of sediment with a vortex tube, the episodic removal of deposits is costly and interrupts the irrigation supply (Atkinson, 1994a, b). A vortex tube at a HPP consists of a steel tube embedded in the 
headrace channel invert, oriented perpendicular or oblique to the flow direction, and extending through the side weir into the residual flow reach (Figure 1a). The tube segment in the headrace channel has a longitudinal slit opening along the soffit through which bed-load particles are entrained. The tube is equipped with a gate valve at the outlet that is only opened when a critical discharge is exceeded. Both the incipient motion of bed-load and the operational scheme of the HPP are considered in the determination of the critical discharge. The combined effect of the approach flow and the pressure gradient between the headrace channel and the residual flow reach leads to the formation of a vortex flow inside the tube that sluices the entrained bed-load to the tube outlet. Suspended sediment concentrations are not altered by the installation of a vortex tube, as merely sediment transported at the bottom of the water column is extracted.

In the case of irrigation channels or HPPs, the extracted sediment is returned to the main river or the residual flow reach, respectively (Figure 1b). Furthermore, the vortex tube concept has also been transferred to desanders of HPPs (Awasthi, 2001; Meier, 2003, 2014) and applied as a bed-load sampling system (Milhous, 1973; Hayward and Sutherland, 1974; Hayward, 1980; O'Leary and Beschta, 1981; Tacconi and Billi, 1987). In the case of vortex tube bed-load samplers, the sediment is diverted to a working pit, where it is collected and weighed.
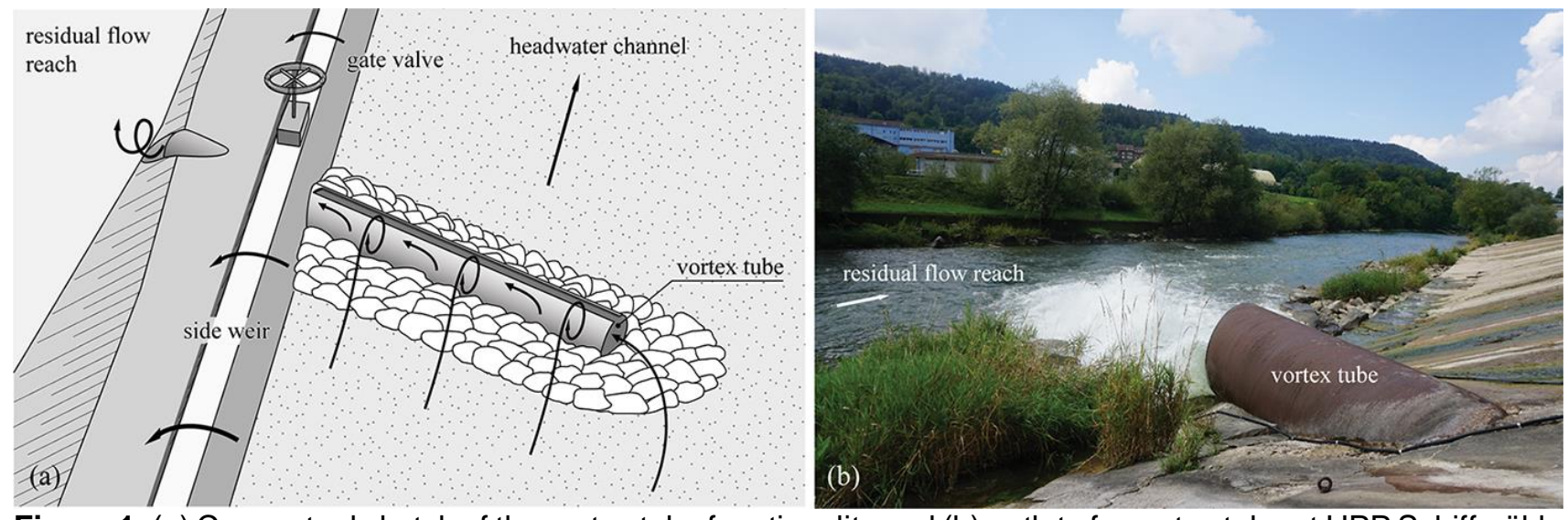

Figure 1. (a) Conceptual sketch of the vortex tube functionality and (b) outlet of a vortex tube at HPP Schiffmühle in operation.

The functionality of a vortex tube mainly depends on the energy head difference between its upstream and downstream end and its location relative to the zone of active bed-load transport. In small streams or irrigation channels, vortex tubes often span the entire channel width (Hayward and Sutherland, 1974). However, several studies suggest that the tube length may be a limiting factor for the diversion capacity (Robinson, 1962; Mtalo, 1988; Atkinson, 1994b). If the channel width surpasses the threshold tube length, either multiple vortex tubes may be installed, or one vortex tube within the predominant bed-load transport zone can be sufficient in the case of laterally unequally distributed bed-load transport (Karaki, 1961).

\section{LABORATORY EXPERIMENTS}

\subsection{Case Study HPPs}

The case study HPPs Schiffmühle and Turgi are located on the $36 \mathrm{~km}$ long lowland Limmat River in Switzerland, which is a tributary to the Aare River and originates from Lake Zurich. It drains an area of 2'400 km² and is a part of the Rhine River basin. The estimated annual bed-load transport in its undisturbed state was 1'500-1'900 m³/a, and its historical morphology was meandering to wandering (Flussbau AG SAH, 2010).

The Limmat River flows through one of the most densely populated areas of Switzerland and is intensely impacted by anthropogenic interferences. Twelve weirs for ROR hydropower production and other purposes interrupt its longitudinal connectivity and cause the deposition of all but fine-grained sediment in their impoundments. In the current state, the estimated bed-load transport amounts to 200-400 m³ a, and the riverbed is heavily armored (Flussbau AG SAH, 2010).

Within the framework of the Swiss Water Protection Act of 2011, a restoration program to mitigate the negative impacts of hydropower production on sediment continuity, fish migration, and the hydrological regime until 2030 is ongoing. All projects intended to restore sediment continuity are required to favor the reestablishment of sediment conveyance over sediment replenishment options. Several HPPs along the Limmat River are subject to restoration projects focusing on sediment continuity, and therefore, the annual bed-load transport is expected to increase again over the next decade. In the river reach where both case study HPPs are located, the estimated future bed-load transport amounts to 1'000-1'100 m3/a (Berner et al., 2014). 
The hydrological data for the Limmat River is obtained from the hydrometric station Baden, Limmatpromenade (Swiss Federal Office for the Environment (FOEN), Station ID 2243). The station is located $5.2 \mathrm{~km}$ upstream of HPP Schiffmühle and $6.7 \mathrm{~km}$ upstream of HPP Turgi, with no major tributaries in between. The long-term mean discharge of the Limmat River is $101 \mathrm{~m}^{3} / \mathrm{s}$ and characteristic flood discharges are $\mathrm{HQ}_{2}=$ $358 \mathrm{~m}^{3} / \mathrm{s}, H Q_{10}=475 \mathrm{~m}^{3} / \mathrm{s}$, and $H Q_{100}=607 \mathrm{~m}^{3} / \mathrm{s}(1951-2016)$.

Due to the strongly armored river bed, full transport of bed material is only expected to occur during extreme flood events $\left(>900 \mathrm{~m}^{3} / \mathrm{s}\right)$, i.e. at discharges beyond the design range of a vortex tube. However, bed-load transport of smaller grain sizes across the armor layer is expected for discharges as low as the mean discharge. Two distinct grain size distributions (GSDs) were thus determined in the scope of both case studies, (i) the GSD of the river bed with the characteristic grain sizes $D_{m}=66 \mathrm{~mm}$ and $D_{90}=147 \mathrm{~mm}$ (VAW, 2001; VAW, 2017) and (ii) the GSD of the transported bed-load with $D_{m}=30 \mathrm{~mm}$ and $D_{90}=66 \mathrm{~mm}$ (Flussbau AG SAH, 2010). The latter was defined based on recommendations for suitable spawning gravel sizes used in sediment replenishment projects.

\subsubsection{HPP Schiffmühle}

The main HPP Schiffmühle is located in a moderate left bend of the Limmat River (Figure 2a), $4 \mathrm{~km}$ upstream of the confluence with the Aare River. A flap gate weir diverts water into the headrace channel separated from the residual flow by a side weir of $400 \mathrm{~m}$ length. A head difference of $3.2 \mathrm{~m}$ is exploited at a design discharge of $108 \mathrm{~m}^{3} / \mathrm{s}$. The seasonally variable environmental flow of at least $8-14 \mathrm{~m}^{3} / \mathrm{s}$ is discharged to the $460 \mathrm{~m}$ long residual flow reach via an additional small HPP, built in 2013. Surplus water exceeding 116$122 \mathrm{~m}^{3} / \mathrm{s}$ is released over the flap gate and the side weir.

The configuration of the headrace channel inlet causes a large portion of the bed-load to be entrained into the headrace channel. The bed-load particles are then deposited mainly in the inside bend along the side weir or transported up to the powerhouse, depending on the hydrological conditions and grain sizes. Prior to the construction of the vortex tube in the year 2003, gravel deposits were extracted in front of the powerhouse approximately every two years. A flood event with a return period of more than 150 years in 1999 required an additional large-scale gravel extraction along the entire headrace channel. The extracted gravel was deposited in the residual flow reach, where it was progressively eroded and entrained into the river flow.

To increase sediment connectivity and to lower the operational costs at HPP Schiffmühle, the engineering firm Flussbau AG SAH designed a vortex tube, which VAW tested in a Froude-scaled hydraulic model. Figure 2a shows the location of the vortex tube in plan view and Figure $1 \mathrm{~b}$ displays the vortex tube in operation.

\subsubsection{HPP Turgi}

HPP Turgi is located in a sharp left bend $1.5 \mathrm{~km}$ downstream of HPP Schiffmühle (Figure $2 \mathrm{~b}$ ). The HPP layout with a long side weir is similar to HPP Schiffmühle, but the headrace channel is located on the left side of the river. A concrete sill is located at the entrance to the residual flow reach. The side weir is $390 \mathrm{~m}$ long and allows a $3.7 \mathrm{~m}$ head difference to be exploited at the design discharge of $35 \mathrm{~m}^{3} / \mathrm{s}$. The residual flow reach is $830 \mathrm{~m}$ long and is fed with an environmental flow of at least $10 \mathrm{~m}^{3} / \mathrm{s}$.

Laboratory tests of a vortex tube at HPP Turgi were conducted at VAW during the planning of a restoration and expansion project elaborated by the engineering firm AF-Consult Switzerland AG. In this project, the design discharge of the HPP and the environmental flow were planned to increase to $80 \mathrm{~m}^{3} / \mathrm{s}$ and $18 \mathrm{~m}^{3} / \mathrm{s}$, respectively. The project would require the side weir to be raised by $0.4 \mathrm{~m}$, increasing the head difference along the weir to an appropriate value for a functional vortex tube. The benefits of a vortex tube would be the increased sediment continuity and decreased operational costs, identical to HPP Schiffmühle. However, the project has not been implemented so far and therefore, HPP Turgi does not feature a vortex tube yet. Figure $2 \mathrm{~b}$ shows the location of the vortex tube as planned with a 3D hydro-numerical model by the commissioned engineering firm and the perimeter of the laboratory Froude-scaled model at VAW.

Although the general setup of both HPPs is similar, the hydraulic conditions at HPP Turgi are considerably less suitable for a vortex tube application. First, HPP Turgi is shut down when the discharge of the Limmat River exceeds $400 \mathrm{~m}^{3} / \mathrm{s}$. This causes distinctly reduced flow velocities in the headrace channel, and it is presumed that bed-load transport is not advancing to the location of the vortex tube and thus cannot be diverted. Therefore, the vortex tube may not be effective precisely during high flows when bed-load transport is most active $\left(>400 \mathrm{~m}^{3} / \mathrm{s}\right.$ ). Second, the water table elevation difference between the headrace channel and the residual flow reach is generally lower at HPP Turgi than at HPP Schiffmühle, potentially preventing an efficient operation of the vortex tube without blocking.

\subsection{Laboratory experiments}

Various geometric configurations of vortex tubes were tested to obtain an optimal configuration (Table 1 for both studies). Hereafter, the setup of both laboratory model studies is described in detail. Note that all values are specified in prototype scale unless otherwise indicated.

\subsubsection{HPP Schiffmühle}


The 1:35 Froude-scaled model of HPP Schiffmühle was built and operated at VAW in the years 2000 and 2001 and included a prototype reach of $460 \mathrm{~m}$, which started $50 \mathrm{~m}$ upstream of the flap gate weir and ended $60 \mathrm{~m}$ upstream of the powerhouse (Figure 2a). The headrace channel had a movable bed with the characteristic grain sizes $D_{m}=1.6 \mathrm{~mm}$ and $D_{90}=3.2 \mathrm{~mm}$ (model scale), and its topography was recreated according to bathymetry data from 1998. The residual flow reach was modeled with a fixed bed, using bathymetry data from 1999 (both datasets collected by Flussbau AG SAH).

The model was appended to the water circulation system of the experimental hall and sediment of the same GSD as the movable bed was supplied to the inflow by a gravimetric sediment feeder. The inflow was controlled according to either constant load cases or hydrographs. The outflow discharge of the headrace channel was held constant at $95 \mathrm{~m}^{3} / \mathrm{s}$, corresponding to the design discharge of the HPP determined at the time of the study. Note that while a more recent assessment has estimated the design discharge at $108 \mathrm{~m}^{3} / \mathrm{s}$, the results presented in this paper refer to $95 \mathrm{~m}^{3} / \mathrm{s}$. The outflow discharge was controlled by an adjustable needle weir, and the discharge was measured with a subsequent rectangular measuring weir. An adjustable weir crest positioned after the stilling basin controlled the outflow of the residual flow reach. The discharge was not directly measured, but determined by subtracting the outflow of the headrace channel from the pump discharge, i.e. model inflow. The diversion efficiency was determined after each run by collecting, drying, and weighing the sediment deposited in the headrace channel and the residual flow reach, respectively.
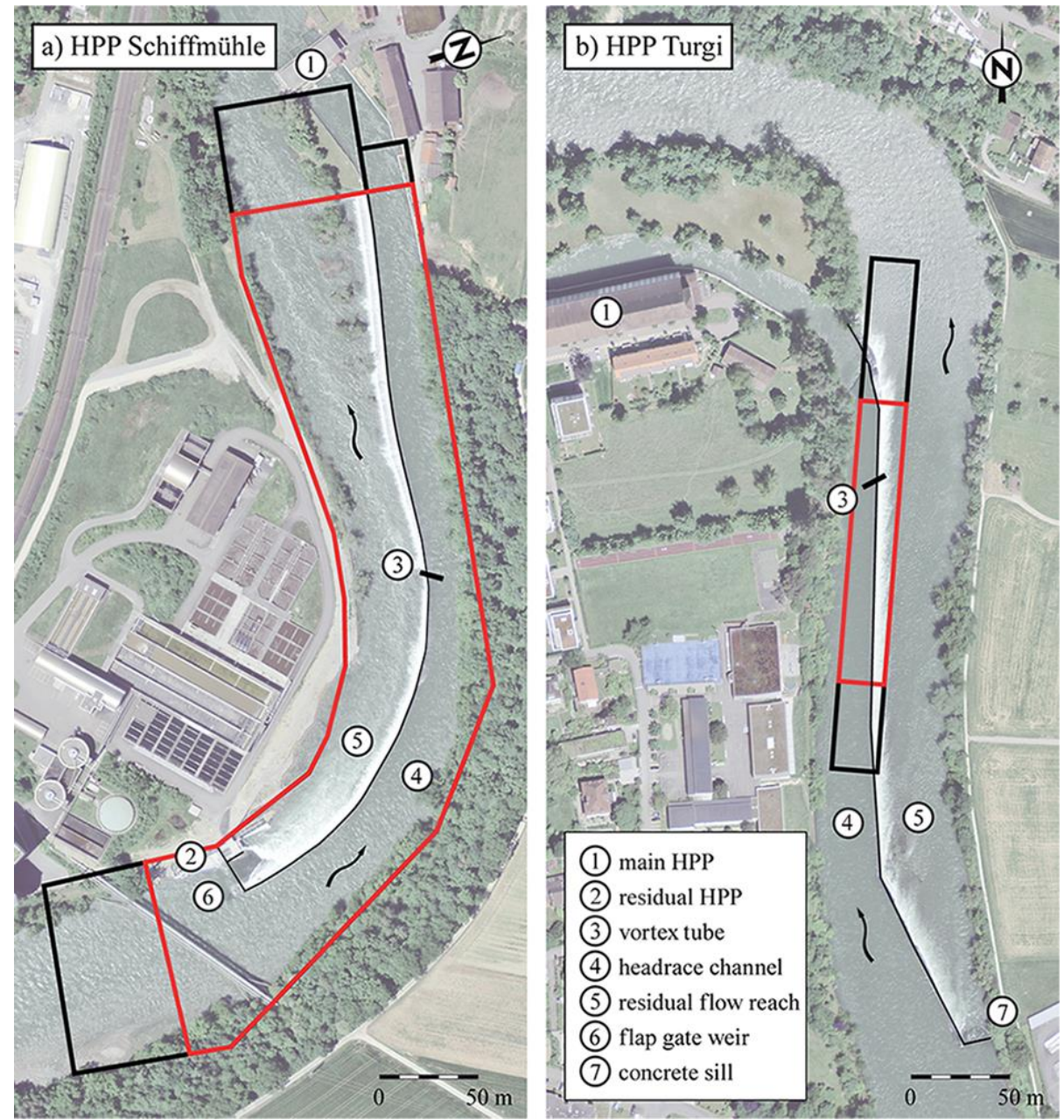

Figure 2. The setup of (a) HPP Schiffmühle and (b) HPP Turgi with the outline of the respective laboratory models in black and the relevant model perimeter in red. (Orthophotos (C) swisstopo)

Four point gauges were installed in the inlet and outlet of the headrace channel and residual flow reach, respectively. The water table elevations were calibrated to fit the backwater curves calculated by the commissioned engineering firm. Velocity measurements were performed with a propeller current meter.

The appropriate sediment feed rate was determined based on the application of different sediment transport formulae and on bathymetry data of the headrace channel in 1998 as well as 1999, after a major flood (> HQ $Q_{150}$ ). Preliminary tests were conducted to adjust the sediment feed rate to correctly reproduce the observed 
depositions in the headrace channel for the year 1999. The hydrograph represented a prototype flood event of three days with $Q=450-639 \mathrm{~m}^{3} / \mathrm{s}$. The lower limit $Q=450 \mathrm{~m}^{3} / \mathrm{s}$ was determined as the critical discharge corresponding to the initiation of bed-load transport, given that there is no significant bed-load input from upstream, e.g. from sediment replenishment activities. A total bed-load transport of $5000 \mathrm{~m}^{3}$ was deduced for the period between the bathymetry measurements of 1998 and 1999 based on these preliminary tests.

Two load cases were defined to test the different vortex tube types, (i) $Q_{v a r}=450-936 \mathrm{~m}^{3} / \mathrm{s}$, representing the year 1999 and (ii) $Q_{\text {stat }}=600 \mathrm{~m}^{3} / \mathrm{s}$. The tested vortex tube parameters are listed in Table 1 and defined in Figure 3.

\subsubsection{HPP Turgi}

Since several design parameters were previously studied for the vortex tube at HPP Schiffmühle and a 3D hydro-numerical model was available, the construction of a scale model of the entire perimeter was not necessary. The laboratory model of HPP Turgi was instead set up as a sectional model at a scale of 1:25 in a straight flume of $10.7 \mathrm{~m}$ length, $1 \mathrm{~m}$ width and $0.82 \mathrm{~m}$ depth (model scale) at VAW. The length of the model perimeter covered $150 \mathrm{~m}$ of the prototype side weir, and its position within the flume was selected to best fit the continuous planform narrowing of the headrace channel (Figure 2b). Upstream and downstream of the model perimeter, any exchange between the two channels was prevented. The headrace channel bed was movable with the characteristic grain sizes $D_{m}=2.8 \mathrm{~mm}$ and $D_{90}=5.9 \mathrm{~mm}$ (model scale), whereas the bed of the residual flow reach was fixed, as the bed-load transport in the residual flow reach was not of interest for the study.

The flume was equipped with two pumps, and the inlet section was designed so that one pump fed the headrace channel and the other pump fed the residual flow reach. Sediment was continuously supplied to the headrace channel by a gravimetric sediment feeder. Feeding sediment to the residual flow reach was not necessary.

The water table elevation in the outlet of the headrace channel was controlled by an adjustable flap gate, which was followed by a V-notch weir to measure the outflow discharge. A needle weir controlled the outflow of the residual flow reach to allow bed-load to exit the flume and be collected in a filtering basket suspended on load cells. The outflow of the residual flow reach was not directly measured, but determined by subtracting the outflow of the headrace channel from the total pump discharge. The described setup allowed the continuous monitoring of the inflow and outflow of both channels as well as the bed-load input to the headrace channel and the bed-load transported out of the residual flow reach. Bed-load carried past the vortex tube was deposited in a trough in front of the flap gate and removed, dried, and weighed after every experiment. The sediment balance was thus measured as an integral value for every run.

Water table elevations were measured with an ultrasonic distance sensor (UDS) and a point gauge installed on a movable cross-beam and flow velocities were measured using a propeller current meter mounted on the same cross-beam.

The model was calibrated to match the water table elevations, flow velocities, and weir overflow of the 3D hydro-numerical model by adjusting the longitudinal slope of the side weir crest. All vortex tube types were tested at a discharge of $400 \mathrm{~m}^{3} / \mathrm{s}$, corresponding to a flood event with a return period of 3-4 years and the maximum discharge at which the HPP is still in operation. Prior to the tests with sediment feed, an armor layer was developed in the headrace channel, corresponding to prototype conditions. For the subsequent test runs, uniform sediment with a grain size of $0.50-0.71 \mathrm{~mm}$ (model scale) was continuously supplied to the headrace channel where it was transported across the armor layer without noticeable interaction. It was found in preliminary tests that larger grain sizes are not transported in the headrace channel at $Q=400 \mathrm{~m}^{3} / \mathrm{s}$. This finding corresponded to the critical grain size transported at $Q=400 \mathrm{~m}^{3} / \mathrm{s}$ in the 3D hydro-numerical model.

The tested vortex tube parameters are listed in Table 1 and defined in Figure 3. Some parameters, e.g. the tube slope $\alpha$ or the height difference of the tube lips $e$ were not or not as extensively tested for HPP Turgi as for HPP Schiffmühle, because their effect was already shown to be negligible or counterproductive. After each run, the vortex tube was replaced with as little disturbance of the bed as possible before the next run began. The diversion efficiency was determined when the sediment balance between total input and total output reached a maximum discrepancy of $\pm 1 \mathrm{~kg}$, corresponding to a transport equilibrium within the flume. 

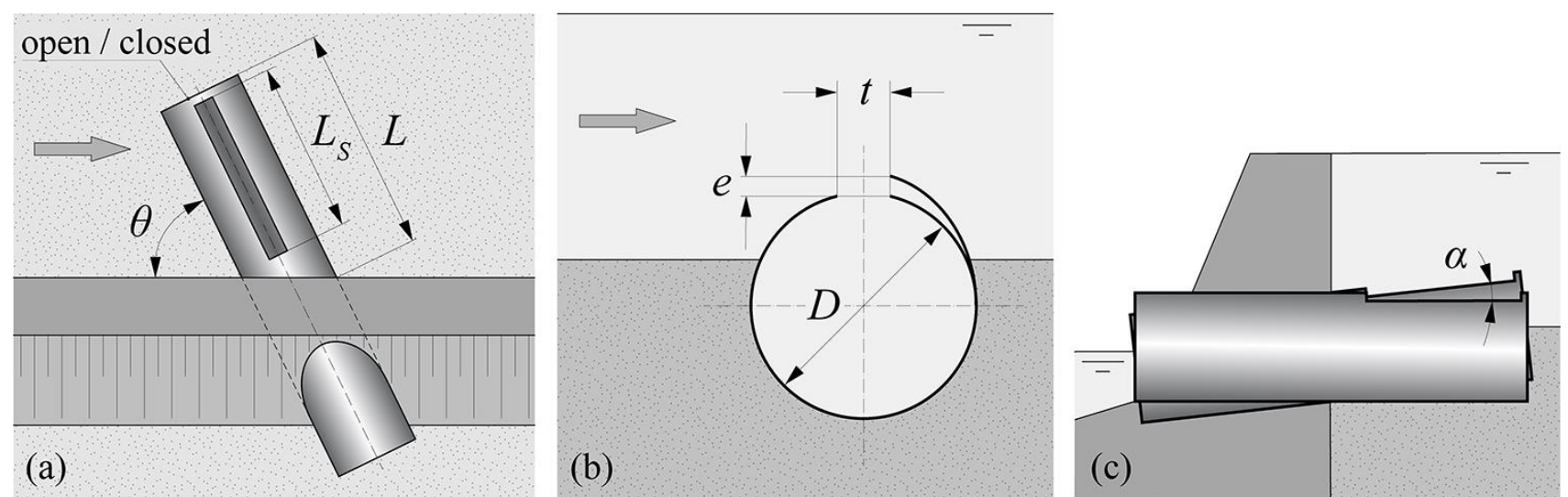

Figure 3. Parameter definition in (a) plan view, (b) cross section, and (c) longitudinal section of a vortex tube embedded in a side weir.

Table 1. Test program for the studies on vortex tubes at HPP Schiffmühle and HPP Turgi. The optimal design identified in each study is marked in bold, and for all other types, the divergent parameters are marked in grey. $\mathrm{O}=$ open and $\mathrm{c}=$ closed upstream tube end. All values are specified in prototype scale.

\begin{tabular}{|c|c|c|c|c|c|c|c|c|c|}
\hline $\begin{array}{c}\text { Vortex } \\
\text { tube }\end{array}$ & $\begin{array}{c}D \\
(\mathrm{~m})\end{array}$ & $\begin{array}{c}t \\
(\mathrm{~m})\end{array}$ & $\begin{array}{c}t D \\
(-)\end{array}$ & $\begin{array}{c}\boldsymbol{e} \\
(\mathrm{m})\end{array}$ & $\begin{array}{c}L \\
(\mathrm{~m})\end{array}$ & $\begin{array}{c}L_{s} \\
(\mathrm{~m})\end{array}$ & $\begin{array}{c}\theta \\
\left({ }^{\circ}\right)\end{array}$ & $\begin{array}{c}\alpha \\
\left({ }^{\circ}\right)\end{array}$ & $\begin{array}{c}0 / c \\
(-)\end{array}$ \\
\hline \multicolumn{10}{|c|}{ HPP Schiffmühle (VAW, 2001) } \\
\hline S1 & 1.05 & 0.95 & 0.9 & 0.67 & 14.7 & 14.7 & 60 & 2 & 0 \\
\hline S2 & 1.05 & 0.95 & 0.9 & 0.67 & 14.7 & 14.7 & 60 & 0 & 0 \\
\hline S3 & 1.05 & 0.35 & 0.33 & 0 & 14.7 & 14.7 & 60 & 0 & 0 \\
\hline S4 & 1.23 & 0.40 & 0.33 & 0 & 8.75 & 8.75 & 60 & 0 & $\mathbf{0}$ \\
\hline S5 & 1.23 & 0.40 & 0.33 & 0 & 12.6 & 12.6 & 60 & 0 & 0 \\
\hline S6 & 1.23 & 0.40 & 0.33 & 0 & 12.6 & 12.6 & 45 & 0 & 0 \\
\hline S7 & 1.61 & 0.46 & 0.29 & 0 & 9.8 & 9.8 & 60 & 0 & 0 \\
\hline S8 & 1.58 & 0.40 & 0.25 & 0.39 & 8.75 & 8.75 & 60 & 0 & 0 \\
\hline S9 & 1.23 & 0.35 & 0.28 & 0.39 & 11.5 & 11.5 & 60 & 0 & 0 \\
\hline \multicolumn{10}{|c|}{ HPP Turgi (VAW, 2017) } \\
\hline $\mathrm{T} 1$ & 1.2 & 0.3 & 0.25 & 0 & 7.9 & 7.9 & 60 & 0 & C \\
\hline T2 & 1.2 & 0.3 & 0.25 & 0.075 & 7.9 & 7.9 & 60 & 0 & c \\
\hline T3 & 1.2 & 0.3 & 0.25 & 0 & 7.9 & 7.9 & 60 & 0 & $\mathbf{0}$ \\
\hline T4 & 1.2 & 0.4 & 0.33 & 0 & 7.9 & 7.9 & 60 & 0 & C \\
\hline T5 & 1.2 & 0.2 & 0.17 & 0 & 7.9 & 7.9 & 60 & 0 & C \\
\hline T6 & 1.2 & 0.3 & 0.25 & 0 & 11.9 & 7.9 & 60 & 0 & c \\
\hline T7 & 1.2 & 0.3 & 0.25 & 0 & 11.9 & 11.9 & 60 & 0 & C \\
\hline T8 & 1.0 & 0.25 & 0.25 & 0 & 7.9 & 7.9 & 60 & 0 & C \\
\hline T9 & 0.8 & 0.2 & 0.25 & 0 & 7.9 & 7.9 & 60 & 0 & C \\
\hline T10 & 1.2 & 0.3 & 0.25 & 0 & 7.9 & 7.9 & 90 & 0 & C \\
\hline T11 & 1.2 & 0.3 & 0.25 & 0 & 7.9 & 7.9 & 75 & 0 & C \\
\hline
\end{tabular}

\section{RESULTS}

The primary outcomes of the laboratory model studies are the diversion efficiency $\eta$, the discharge extraction ratio $Q_{T} / Q$, with $Q_{T}=$ discharge through the vortex tube and $Q=$ total inflow discharge, and the tendency for blockage at a particular water table elevation difference $\Delta z_{w}$. When comparing the results of both studies, a few differences between the two studies have to be taken into account. As shown in Table 1, the study on HPP Turgi was more thorough in varying parameters one by one. Note also that for HPP Schiffmühle, not all parameters were tested for the same load case (Table 2). Furthermore, the diversion efficiency of the vortex tube at HPP Schiffmühle was determined in a scale model covering the entire river width and correctly representing the channel curvature (Figure 2a). In contrast, the sectional model of HPP Turgi did not reproduce the channel curvature, and therefore the effect of secondary flow concentrating the bed-load transport on the right side of the headrace channel was not replicated. The model also did not cover the entire width of either channel (Figure 2b). The resulting diversion efficiencies for HPP Turgi can therefore not be interpreted as absolute values, but only serve the purpose of identifying the most suitable vortex tube design. The combined evaluation of both studies nevertheless allows the assessment of the influence of single parameters. 
The diversion efficiencies $\eta$ of the evaluated vortex tube configurations are summarized in Table 2. The configurations S1 and S2 were the starting point for the tests on HPP Schiffmühle, corresponding to the design proposed by the commissioned engineering firm. The longitudinal vortex tube slope $a$ does not significantly influence $\eta$. However, the protrusion of the elevated vortex tube part of S1 caused standing waves in the wake of the tube, which is undesirable from an operational viewpoint. The presence of a lip height difference $e$ does not have a positive impact on $\eta$ either. While the higher downstream lip acts as a frontal collector and may, therefore, catch saltating grains, the predominant impact of the protruding lip is the disturbance of the flow and the triggering of standing waves (S1, S2, S8, S9). The reduction of the upstream flow angle $\theta$ from $60^{\circ}$ to $45^{\circ}$ (S6) caused depositions within the tube that eventually resulted in its complete blockage. The effects of the tube diameter $D$, the tube length $L$, and the slit ratio $t / D$ cannot be determined unambiguously, because they were varied simultaneously and their impacts are therefore superimposed (Table 1). Overall, the vortex tube configuration of S4 was identified as the best option.

The vortex tube discharge $Q_{T}$ was indirectly evaluated based on velocity measurements within the vortex tube. The maximal $Q_{T}$ of $6.5 \mathrm{~m}^{3} / \mathrm{s}$ was determined at the inflow discharge $Q=400 \mathrm{~m}^{3} / \mathrm{s}$ and the maximal extraction ratio $Q_{T} / Q$ therefore amounts to $6.8 \%$ for the headrace channel discharge of $95 \mathrm{~m}^{3} / \mathrm{s}$.

For $Q>600 \mathrm{~m}^{3} / \mathrm{s}$, the water table elevation difference $\Delta z_{w}$ fell below $1 \mathrm{~m}$, and short-term blockages were observed, also for the best option S4. The blockages generally dissolved after a short time, particularly once the discharge was reduced to lower values, thereby increasing $\Delta z_{w}$.

Table 2. Diversion efficiencies $\eta$ determined for HPP Schiffmühle. Not all tests were conducted for the same load case, some for the hydrograph $Q_{v a r}=450-639 \mathrm{~m}^{3} / \mathrm{s}$, others for the steady $Q_{\mathrm{stat}, 600}=600 \mathrm{~m}^{3} / \mathrm{s}$ and equilibrium conditions. S2, S3, and S6 were blocked permanently so that no diversion efficiency could be measured.

\begin{tabular}{lccccccccc}
\hline Vortex tube & S1 & S2 & S3 & S4 & S5 & S6 & S7 & S8 & S9 \\
\hline Load case & $Q_{\text {var }}$ & $Q_{\text {var }}$ & $Q_{\text {var }}$ & $Q_{\text {var }}$ & $Q_{\text {stat }, 600}$ & $Q_{\text {stat }, 600}$ & $Q_{\text {stat }, 600}$ & $Q_{\text {stat, } 600}$ & $Q_{\text {stat,600 }}$ \\
\hline $\boldsymbol{\eta}(\%)$ & $87 \%$ & blocked & blocked & $94 \%$ & $89 \%$ & blocked & $77 \%$ & $78 \%$ & $91 \%$ \\
\hline
\end{tabular}

\subsection{HPP Turgi}

The diversion efficiencies $\eta$ of the evaluated vortex tube configurations are summarized in Table 3 . The vortex tube configuration T1 with a diversion efficiency of $\eta=59 \%$ was the starting point for the tests on HPP Turgi, corresponding to the design proposed by the commissioned engineering firm (Figure 4a). The subsequent variation of each parameter showed no significant impact of the lip height difference $e$ (T2) and the upstream flow angle $\theta(\mathrm{T} 10, \mathrm{~T} 11)$. The variation of the slit width $t$ produced ambiguous results, with lower $\eta$ measured for both a larger (T4) and a more narrow slit width (T5). The extension of the vortex tube length $L$ without a longer slit length $L_{s}$ did not affect $\eta$ (T6) but shifted the zone of bed-load extraction to the location of the slit. However, when the slit length was adapted to the elongated vortex tube, $\eta$ was enhanced (compare T6 with T7). The reduction of the tube diameter $D$ slightly enhanced $\eta$ for T8 and T9. A brief blockage was observed for T9, which dissolved after a short time. The most significant increase in $\eta$ was attained by opening the vortex tube's upstream end in the headrace channel, extending the river bed zone affected by the sluicing (T3, Figure 4b). Therefore, T3 was identified as the best option with the highest $\eta$.

Table 3. Diversion efficiencies $\eta$ determined for HPP Turgi. All tests were conducted at a steady discharge of $Q=400 \mathrm{~m}^{3} / \mathrm{s}$ and equilibrium conditions. T3 was tested twice.

\begin{tabular}{lccccccccccc}
\hline Vortex tube & T1 & T2 & T3 & T4 & T5 & T6 & T7 & T8 & T9 & T10 & T11 \\
\hline $\boldsymbol{\eta}(\%)$ & $59 \%$ & $58 \%$ & $83 / 80 \%$ & $52 \%$ & $45 \%$ & $54 \%$ & $71 \%$ & $62 \%$ & $\begin{array}{c}65 \%, \\
\text { blocked }\end{array}$ & $63 \%$ & $61 \%$ \\
\hline
\end{tabular}

The discharge extracted by the vortex tube $Q_{T}$ was determined for $Q=150$ and $270 \mathrm{~m}^{3} / \mathrm{s}$ and water elevation differences of $\Delta z_{W}=1-3.5 \mathrm{~m}$ between the two channels. The maximal value of $Q_{T}$ is expected to occur for uninhibited outflow into the residual flow reach, i.e. for $\Delta z_{W} \geq 3 \mathrm{~m}$. For $Q=270 \mathrm{~m}^{3} / \mathrm{s}, Q_{T}$ varied between $1.8 \mathrm{~m}^{3} / \mathrm{s}$ for $\Delta z_{W}=1.2 \mathrm{~m}$ and $5.2 \mathrm{~m}^{3} / \mathrm{s}$ for $\Delta z_{W}=3 \mathrm{~m}$. For $Q=150 \mathrm{~m}^{3} / \mathrm{s}, Q_{T}$ varied between $2.6 \mathrm{~m}^{3} / \mathrm{s}$ for $\Delta z_{W}=$ $1.1 \mathrm{~m}$ and $4.1 \mathrm{~m} / \mathrm{s}$ for $\Delta z_{W}=2.4 \mathrm{~m}$. The extraction efficiency $Q_{T} / Q$, therefore, lies between 2.2 and $6.5 \%$ for a design discharge of $80 \mathrm{~m}^{3} / \mathrm{s}$ in the headrace channel. It was not possible to assess $Q_{T}$ for $Q>270 \mathrm{~m}^{3} / \mathrm{s}$ due to the limited capacity of the V-notch measurement weir at the end of the headrace channel.

The effect of small water table elevation differences $\Delta z_{W}$ on the likelihood of clogging was tested with the vortex tube T3 and $Q=500 \mathrm{~m}^{3} / \mathrm{s}$. During this test run, $\Delta z_{w}$ varied between $0.54 \mathrm{~m}$ and $0.65 \mathrm{~m}$ and short-term blockages occurred. The blockages were not permanent and repeatedly dissolved spontaneously. 

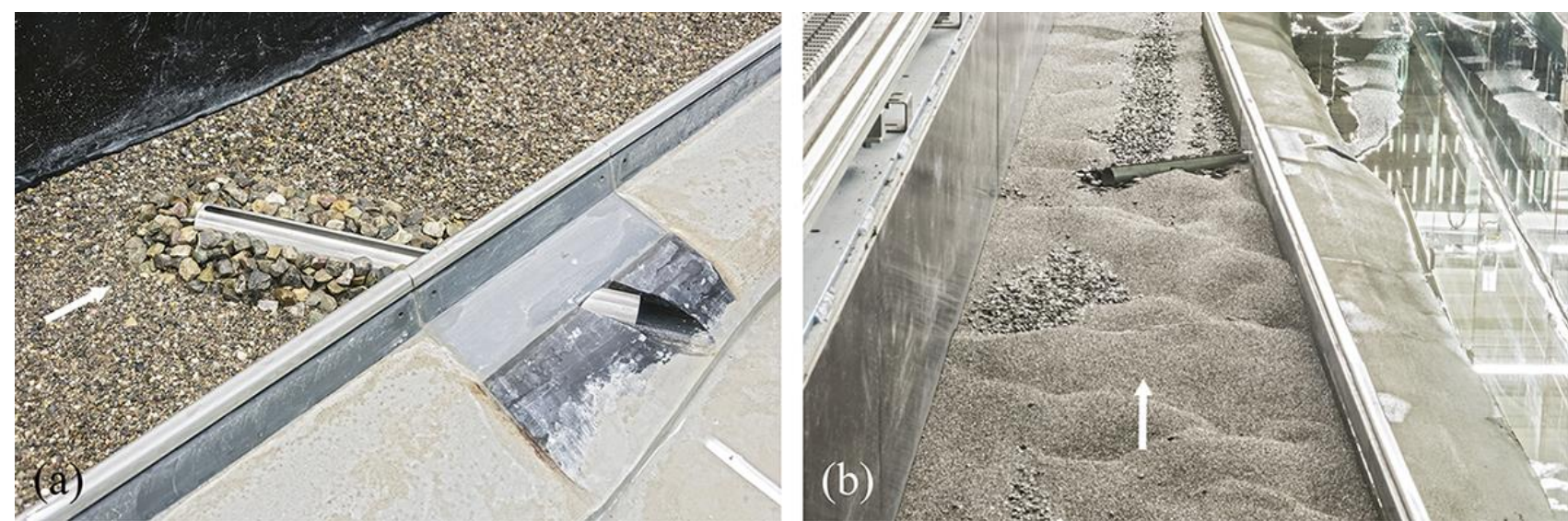

Figure 4. Vortex tube of (a) type T1 prior to a test run with the stable armor layer in the headrace channel and riprap around the vortex tube and (b) type T3 after a test run. In (b), the diversion effect of the vortex tube is clearly visible, as the river bed behind the vortex tube is only slightly covered with the fine bed-load material. On the left side of the channel, sediment is transported past the influence zone of the vortex tube.

\section{DISCUSSION}

The major influencing factors on the functionality of a vortex tube are divided into two categories: (i) geometrical design parameters and (ii) hydraulic boundary conditions. The relevant design parameters determined from two Froude-scaled laboratory studies are the diameter $D$, length $L$, slit ratio $t / D$, the upstream flow angle $\theta$, and the open or closed upstream end of the tube.

It is recommended that the diameter of the vortex tube should neither be too small, as the vortex flow may fail to develop properly, nor too large, to reduce construction costs. The choice of the vortex tube diameter should be adapted to the grain sizes present in the transported material. In the case of HPPs Turgi and Schiffmühle, a diameter of approx. $1.2 \mathrm{~m}$ is suitable. Smaller diameters, i.e. 0.4-0.8 m, are reported for vortex tubes used in desanders of hydropower schemes (Awasthi, 2001; Meier, 2014).

The slit width $t$ is related to the tube diameter with the slit ratio $t / D$. The optimal slit ratios identified here are 0.33 for HPP Schiffmühle and 0.25 for HPP Turgi. Other studies recommend similar or lower ratios, e.g. $t / D=$ 0.15-0.3 in Atkinson (1994b) or $t / D=0.1-0.2$ in Mtalo (1988).

Robinson (1962) recommends that the tube length $L$ should be selected based on the tube diameter with $L D \leq 20$ and to adhere to a maximal length of $4.5 \mathrm{~m}$. For HPPs Schiffmühle and Turgi, optimal tube lengths of $8.75 \mathrm{~m}$ and $7.9 \mathrm{~m}$ were determined. The functioning of longer vortex tubes compared to the length recommended by Robinson (1962) is attributed to the greater water table elevation difference and thus higher energy head generating the vortex flow. Furthermore, the study on HPP Turgi revealed the importance of an open upstream tube end, which extends the influence zone of the vortex tube. The open upstream end might be another reason for the high efficiency of longer vortex tubes, due to the additional momentum introduced in the longitudinal direction. Previous studies on vortex tubes did not consider the option of an open tube end, because the vortex tubes often span the entire channel width (e.g. Hayward and Sutherland, 1974; Awasthi, 2001).

The recommended upstream flow angle ranges from $\theta=45^{\circ}$ to $90^{\circ}$ (Robinson, 1962; Atkinson, 1994b). An oblique inflow into the vortex tube $\left(\theta<90^{\circ}\right)$ may favor the development of the vortex flow and enhance the sluicing effect. However, a small upstream flow angle may, in turn, impair the development of the vortex flow. In the present study, the highest diversion efficiencies were obtained for $\theta=60^{\circ}$. When determining the upstream flow angle, the curvature of the headrace channel has to be taken into account.

The extraction ratio $Q_{T} / Q$ determined in the present study are at the lower end of the reported range of 5$15 \%$ (Robinson, 1962; Mtalo, 1988). Although lower extraction ratios are generally beneficial, it is not of utmost importance in the case of HPPs Schiffmühle and Turgi, because the vortex tube is only in operation when the total discharge surmounts the design discharge of either HPP and therefore no water is lost for hydropower production.

In the HPP Schiffmühle study, no erosion protection measures were taken in the vicinity of the vortex tube. Due to the strong interactions between the vortex tube and the flow in the headrace channel, large scour holes were observed. Based on this finding, the immediate surroundings of the vortex tube were protected with riprap 
in the HPP Turgi study, which is a general recommendation for the design of vortex tubes (Figure 4a). However, the maximal elevation of the riprap should not exceed half the height of the vortex tube. Otherwise, protruding blocks might cause strong turbulence and thus deflect grains past the slit.

A water table elevation difference of at least $1 \mathrm{~m}$ is recommended to avoid short-term blockages. In some cases, such blockages dissolve after a short time, while in other cases, they may be permanent and impair the bed-load diversion. This parameter is particularly important since the lowest values generally occur during flood events when bed-load transport is most active.

\section{CONCLUSIONS AND OUTLOOK}

This paper reports the results of two laboratory studies on the optimization of the vortex tube design for the hydraulic and sedimentological conditions at two ROR HPPs in Switzerland. The goal of both studies was to adapt the sediment diversion concept originally developed for relatively narrow irrigation channels with fine sediment to wider headrace channels in gravel-bed rivers. The energy head difference between the headrace channel and the residual flow reach is identified as a crucial parameter and should be larger than $1 \mathrm{~m}$ to ensure efficient bed-load diversion. Furthermore, the geometry of the vortex tube, e.g. its diameter or slit width, should be adapted to the grain sizes transported in a specific river. If the vortex tube does not span the entire channel width, an open upstream end is recommended to increase the zone of influence and thus the diversion efficiency. S4 for HPP Schiffmühle and T3 for HPP Turgi were identified as the most suitable vortex tube designs with diversion efficiencies of $94 \%$ and $80 \%$, respectively. Our findings demonstrate that vortex tubes are an appropriate structural measure to re-establish sediment continuity at hydraulic structures, primarily where the upstream and downstream channel are located in close proximity.

The assessment of the diversion efficiency solely based on laboratory experiments, however, remains challenging due to uncertainties in the boundary conditions and possible weaknesses in the scaled representation of the complex processes occurring in the vicinity of a vortex tube (Atkinson, 1994a, b). Therefore, further research focusing on the diversion efficiency of prototype vortex tubes is necessary. In the scope of the European research project FITHydro (Fishfriendly Innovative Technologies for Hydropower), we installed a passive acoustic bed-load monitoring system with a geophone and an accelerometer at HPP Schiffmühle in 2018. The goal is to quantitatively assess the prototype diversion efficiency during flood events and improve the recommendations on vortex tube design and operation. Furthermore, the collected data will be combined with additional field data on flow velocities, bathymetry, fish migration, and habitat monitoring to increase the understanding on the overall impact of HPPs on the availability and quality of fish habitat.

\section{ACKNOWLEDGMENTS}

The experimental studies on vortex tubes at HPP Schiffmühle and HPP Turgi have both been commissioned by the HPP operator, Limmatkraftwerke AG, Baden, Switzerland. The authors kindly acknowledge the supply of operational data and permission to publish the results of the experimental studies. The final stage of this work has been supported by the European Union's Horizon 2020 research and innovation programme under the grant agreement No. 727830, FITHydro (Fishfriendly Innovative Technologies for Hydropower). The authors would also like to thank the State Secretariat for Education, Research and Innovation (SERI), Switzerland, for their support.

\section{REFERENCES}

Atkinson, E. (1994a). Vortex-Tube Sediment Extractors. I: Trapping Efficiency. J. Hydraul. Eng., 120(10), 11101125.

Atkinson, E. (1994b). Vortex-Tube Sediment Extractors. II: Design. J. Hydraul. Eng., 120(10), 1126-1138.

Awasthi, A.K. (2001). Desanding for small hydro - an innovative approach. $2^{\text {nd }}$ International Conference on Silting Problems in Hydropower Plants, Ed. S.P. Kaushish, Bangkok, Thailand, 83-89.

Berner, P., Burger, S., and Richard, U. (2014). Sanierung Geschiebehaushalt - Strategische Planung für Aare, Reuss, Limmat, Rhein und ihre Seitengewässer (Restoration of the sediment balance - Strategical Planning for the Aare River, Reuss River, Limmat River, Rhein River, and their tributaries). Technical Report, Department of Construction, Transport, and Environment Canton of Argovia, Aarau, Switzerland [in German].

Boes, R.M. (ed.) (2015). Proceedings of the $1^{\text {st }}$ International Workshop on Sediment Bypass Tunnels. VAWMitteilungen 232, Laboratory of Hydraulics, Hydrology and Glaciology (VAW), ETH Zurich, Switzerland.

Boes, R.M., Albayrak, I., Friedl, F., Rachelly, C., Schmocker, L., Vetsch, D., Weitbrecht, V. (2017). Geschiebedurchgängigkeit an Wasserkraftanlagen (Bed-load conveyance at hydropower plants). Aqua Viva, 2, 23-27 [in German].

Bunte, K. (2004). Gravel Mitigation and Augmentation below Hydroelectric Dams: A Geomorphological Perspective. Report, USDA Forest Service, Fort Collins, Colorado.

Flussbau AG SAH (2010). Geschiebehaushaltsstudie Sihl - Limmat (Study on the sediment balance in the Sihl and Limmat River). Technical Report, Construction department Canton of Zurich, Electricity Company of the 
City of Zurich, Department of Construction, Transport, and Environment, Canton of Argovia, and Limmatkraftwerke AG, Zurich, Switzerland [unpublished, in German].

Hayward, J.A. and Sutherland, A.J. (1974). The Torlesse stream vortex-tube sediment trap. J. Hydrol. (NZ), 13(1), 41-53.

Hayward, J.A. (1980). Hydrology and stream sediments in a mountain catchment. Special Publication No. 17, Tussock Grasslands and Mountain Lands Institute, Lincoln College, Canterbury, New Zealand.

Karaki, S.S. (1961). A Final Report on a Model Investigation of the Sediment Ejector for the Trimmu-Sidhnai Link Canal. Technical Report CER61SSK81, Colorado State University.

Kondolf, G.M. (1997). Hungry Water: Effects of Dams and Gravel Mining on River Channels. Environ. Manage., 21(4), 533-551.

Meier, J. (2003). Leistungsfähiger Sandabzug für moderne Entsander in Neu- und Umbauprojekten (Efficient sand removal for modern desanders in new and upgrade projects). Wasser, Energie, Luft, 95(7/8), 205-206 [in German].

Meier, J. (2014). Entsanderanlagen für Wasserkraftwerke - Stand der Technik (Desanding facilities for hydropower plants - state of the art). HYDRO zek, August, 91-93 [in German].

Milhous, R.T. (1973). Sediment transport in a gravel-bottomed stream. Dissertation. Oregon State University.

Mtalo, F. (1988). Geschiebeabzug aus Kanälen mit Hilfe von Wirbelröhren (Sediment extraction from channels with vortex tubes). Report No. 58, Hydraulic Research Institute Obernach, Technical University of Munich, Germany [in German].

O'Leary, S.J. and Beschta, R.L. (1981). Bedload transport in an Oregon coast range stream. J. Am. Water Resour. Assoc., 17(5), 886-894.

Robinson, A.R. (1962). Vortex Tube Sand Trap. Trans. ASCE, 127(3), 391-424.

Sumi, T. (ed.) (2017). Proceedings of the $2^{\text {nd }}$ International Workshop on Sediment Bypass Tunnels, Kyoto University, Kyoto, Japan.

Tacconi, P. and Billi, P. (1987). Bed load transport measurements by the vortex-tube trap on Virginio Creek, Italy. Sediment Transport in Gravel-Bed Rivers, Eds. C.R. Thorne, J.C. Bathurst, and R.D. Hey, John Wiley \& Sons New York, 583-606.

VAW (2001). Kraftwerk Schiffmühle (Hydropower plant Schiffmühle). VAW-Report 4158, Laboratory of Hydraulics, Hydrology and Glaciology (VAW), ETH Zurich, Switzerland [unpublished, in German].

VAW (2017). Wirbelröhre Kraftwerk Turgi (Vortex tube hydropower plant Turgi). VAW-Report 4343, Laboratory of Hydraulics, Hydrology and Glaciology (VAW), ETH Zurich, Switzerland [unpublished, in German].

Wohl, E., Bledsoe, B.P., Jacobson, R.B., Poff, N.L., Rathburn, S.L., Walters, D.M., and Wilcox, A.C. (2015a). The Natural Sediment Regime in Rivers: Broadening the Foundation for Ecosystem Management. BioScience, 65(4), 358-371.

Wohl, E., Lane, S.N., and Wilcox, A.C. (2015b). The science and practice of river restoration. Water Resour. Res., 51, 5974-5997. 